\title{
An IoT based Warehouse Intrusion Detection (E-Perimeter) and Grain Tracking Model for Food Reserve Agency
}

\author{
Sipiwe Chihana \\ Department of Computer Science \\ Mulungushi University \\ Kabwe, Zambia
}

\author{
Jackson Phiri \\ Department of Computer Science \\ University of Zambia \\ Lusaka, Zambia
}

\author{
Douglas Kunda \\ Department of Computer Science \\ Mulungushi University \\ Kabwe, Zambia
}

\begin{abstract}
Zambia's agricultural sector through Food Reserve Agency (FRA) while still underdeveloped faces many challenges that range from marketing, spoilage, infestations, and theft at site, spillage and storage among others. The methods used by FRA in their business processes are largely manual as there are no systems in place. In order to help curb these problems, this paper proposed and developed novel methods that can be used to sense real-time warehouse intrusion and grain tracking within the FRA circulation. The IoT based prototype model made use of the APC220 transceiver, GSM, GPRS, RFID, PIR and cloud storage. To curb theft of grain at storage points, the system used motion sensing through the use of PIR sensors, wireless radio communication module and the GSM/GPRS technologies such that when anyone comes in the range of PIR sensor, then the sensor will send a logic signal to the microcontroller. Lastly, the RFID combined with GSM and Arduino microcontroller responsible for grain tracking. From the results obtained in the experiment conducted it is believed that once this technology is adopted, theft will be reduced and grain management in the FRA satellite Depots dotted around the country will improve.
\end{abstract}

Keywords-Internet of things; motion sensing; RFID; cloud storage; GSM/GPRS

\section{INTRODUCTION}

Food is a fundamental human need and as such food security is cardinal in any country [1]. The Food and Agriculture Organization (FAO) defines food security as a condition whereby all people, at all times, have physical and economic access to sufficient, safe, and nutritious food to meet their dietary needs and food preferences for an active and healthy life [2]. In Zambia government through the FRA ensures countrywide food sustainability and offers market access for rural based small holder farmers by maintaining a sustainable countrywide strategic food reserve [3]. Additionally FRA acts as a macro-economic stabilizer for food grown in the country, such as maize which is the nation's staple crop.

The government of Zambia through FRA despite ensuring national food security, almost every year huge quantities of food are lost due to many factors such as spoilage, infestations, theft and spillage during transporting [4] in [1]. It has also been noted that FRA faces challenges in efficient management of inventory [1], this is according to the auditor general's report that was carried out between 2006 and 2009 to review the performance of FRA [5]. This was the first ever official audit report on food reserve agency grain management, according to the report FRA experienced maize shortages of 115, $516 \times$ $50 \mathrm{~kg}$ bags valued at ZMK4, 274, 092, 000 (old currency) at various depots. These losses were attributed to theft and grain spoilage at the warehouse depots [5].Most of the challenges reported were as a result of poor monitoring and a poor inventory management approach which is largely manual and paper based [1]. The report further stated that FRA faces challenges to effectively monitor and inspect its storage facilities and organized crime was another factor leading to shortages usually at the time of dispatch. Inorder to validate the report by the auditor general's findings as far as grain mismanagement is concerned, independent baseline studies by [1] and [6]were conducted between 2015 and 2017 respectively, this was in a sponsored joint research study by University of Zambia in partnership with Tshwane University of Technology in South Africa [6]. The baseline studies report that FRA as reported in the auditor general's findings still had challenges of manual report generation, lack of connectivity to remote warehouses [6], failure to track stock on demand [6], theft [1] and spoilage of stock due to lack of environmental monitoring [6] [1]. [7] Notes that efforts to improve upon food security subsequently reducing hunger especially in the world's poorest countries should give priority to the issue of crop losses.

However it is hardly possible to give priority to the issues of crop losses and ensure food security in the absence of proficient delivery, control and tracking mechanisms across the supply chain. As a result of the challenges identified at FRA, there is therefore need for better management of the grain through automation of the processes. [8] Augments that as the world is shifting towards new technologies and applications it is a necessary goal to adopt new technologies in agriculture as well. Therefore there is need to have a precise, and appropriate technique of tracking of the grain bags and managing the warehouse or storage facilities. This shall be done in order to reduce theft of the grain and ensure management and monitoring of the grain in a credible and efficient manner.

Our major objectives therefore in this paper are to design a warehouse Intrusion detection (E-Perimeter) and grain tracking Model based on IoT, cloud storage and mobile communication for securing grain. To also develop methods based on the 
model for accessing grain status information in real-time and lastly to Develop a prototype application based on the web to provide real-time access to warehouse intrusion alerts and current warehouse grain quantities.

\section{LITERATURE REVIEW}

This section explores the use of internet of things (IoT) and their application. The literature review creates a significant base for understanding the concept of IoT and their applications in intrusion detection and grain tracking. Lastly related works of previous research are presented.

\section{A. Internet of Things}

With advancement in technology, many sectors have seen growth and improvement in service delivery. Today, many areas such as health, transport and logistics, retailing among others have adopted the use of internet of things (IoT). Agricultural sector has not been left out on this use of IoT. [9] Adds that special tools and strategies are handy for improvement of farming. According to the UN Food and Agriculture Organization [9], in order to feed the developing populace of the earth, the world will want to produce $70 \%$ extra food in 2050 than it did in 2006 [9]. To meet this demand, farmers and agricultural agencies are shifting towards the Internet of Things for analytics and greater manufacturing capabilities. Internet of Things (IoT) can play a great role in growing productivity, acquiring large global market and monitoring latest traits of crops [10] Defines IoT as the system of physical objects or things hooked up with hardware, software, sensors, and system connectivity which empowers these objects to gather and alternate information. IoT makes use of different kinds of protocols to work with exclusive objects. In a related study [11]adds that IoT is a network of ordinary objects which are embedded with technologies that helps to communicate and engage inside themselves and exterior environment, this in-turn affords Intellect to the objects thereby making people's lives convenient. IoT also provides networking to connect people, things, applications, and data through the Internet to enable remote control, management, and interactive integrated services [12].Fig 1 below shows a summary of the IoT definition.

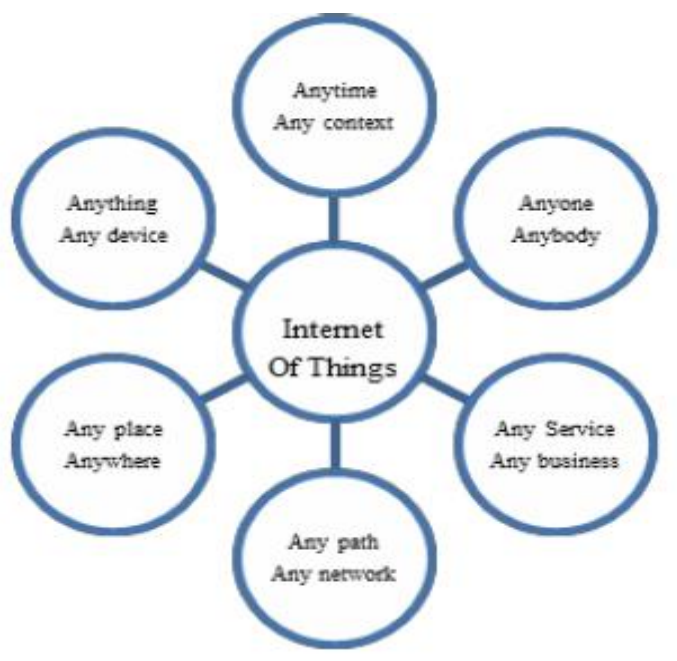

Fig. 1. IoT Definition/Concept [13] [15] [16].
1) Applications of IoT: IoT technology has many applications and can be put to many uses, below is table 1 showing the IoT uses among others:

TABLE I. IOT SMART APPLICATIONS AND ITS SERVICES [12]

\begin{tabular}{|l|l|l|}
\hline \multirow{2}{*}{ No. } & \multicolumn{2}{|l|}{ Application of Internet of things } \\
\cline { 2 - 3 } & Service Domain & Services \\
\hline 1 & Smart Home & Entertainment, Internet Access \\
\hline 2 & Smart Office & $\begin{array}{l}\text { Secure File Exchange, Internet Access, } \\
\text { VPN, B2B }\end{array}$ \\
\hline 3 & Smart Retail & $\begin{array}{l}\text { Customer Privacy, Business } \\
\text { Transactions, Business Security, } \\
\text { Business Security, B2B, Sales \& } \\
\text { Logistics Management }\end{array}$ \\
\hline 5 & Smart City & $\begin{array}{l}\text { City Management, Resource } \\
\text { Management, Police Network, Fire } \\
\text { Department Network, Transportation } \\
\text { Management, Disaster Management }\end{array}$ \\
\hline 6 & Smart Agriculture & $\begin{array}{l}\text { Area Monitoring, Condition Sensing, } \\
\text { Fire Alarm, Trespassing }\end{array}$ \\
\hline 7 & $\begin{array}{l}\text { Smart Energy \& } \\
\text { Fuel }\end{array}$ & $\begin{array}{l}\text { Pipeline Monitoring, Tank Monitoring, } \\
\text { Power Line Monitoring, Trespassing \& } \\
\text { Damage Management }\end{array}$ \\
\hline \multirow{2}{*}{$\begin{array}{l}\text { Smart } \\
\text { Transportation }\end{array}$} & $\begin{array}{l}\text { Road Condition Monitoring, Traffic } \\
\text { Status Monitoring, Traffic Light Control, } \\
\text { Navigation Support, Smart Car support, } \\
\text { Traffic Information Support, Intelligent } \\
\text { Transport System (ITS) }\end{array}$ \\
\hline
\end{tabular}

2) IoT Architecture: Architecture of IoT according to [13] in [11] is broadly classified into 4 layers. Figure 2 shows the architecture as classified by [13].

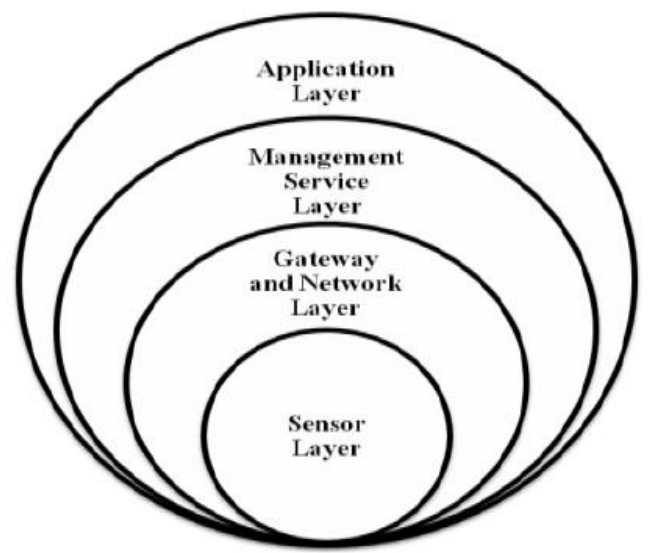

Fig. 2. Layered Architecture of IOT [11] [12] [14].

\section{a) Sensor Layer}

According to [15] and [12], this is lowest layer of IOT Architecture, which consists of sensor networks, embedded systems, RFID tags and readers or other smooth sensors which are one-of-a-kind varieties of sensors deployed in the field. Each of these sensors has identification and information storage (e.g. RFID tags), information collection (e.g. sensor networks). 


\section{b) Gateway and Network Layer}

This layer is accountable for transferring the records gathered through sensors to the subsequent layer, this is according to [11]. The writer notes that this layer ought to support scalable and flexible requirements usual protocol for transferring facts from heterogeneous devices (Different sorts of sensor nodes). This Layer further ought to have high performance and sturdy network. Lastly it has to also assist more than one organization to dialog independently.

\section{c) Management Service Layer}

This layer acts as an interface between the Gateway Network layer and the application layer in bidirectional mode [11]. It is responsible for gadget administration and information management and accountable for capturing massive amount of the raw data and extracting applicable information from the stored records as well from the real time data. Security and privacy of the facts should be ensured [11].

\section{d) Application Layer}

This is the top most layer of IoT which affords a user interface to access a range of purposes to one-of-a-kind users [11]. The functions can be used in more than a few sectors like transportation, health care, agriculture, supply chain, government, retail etc. [11] [14]

\section{3) IoT Elements}

\section{a) Sensing}

[16] Notes that the first step in IOT workflow is gathering data at a "point of activity." This can be information captured by an appliance, a wearable device, a wall set up control or any number of frequently found devices. [16] Further adds that the sensing can be biometric, biological, environmental, visual or audible (or all the above). The special component in the context of IOT is that the machine doing the sensing is not one that commonly gathered statistics in this way. Sensing technological know-how precise to this reason is required [16].

\section{b) Communication}

[16] Augments that IOT gadgets require ability for transmitting the information sensed at the device level to a Cloud-based provider for subsequent processing. This is where the great value inherent in IOT is created. This however requires either $\mathrm{Wi}-\mathrm{Fi}$ (wireless $\mathrm{LAN}$ based totally communications) or WAN (wide area network... i.e. cellular) communications, [16].adds.

\section{c) Cloud based Capture}

[16] Observes that Gathered data is transmitted to a cloud based service where the information coming in from the IOT device is aggregated with other cloud based data to provide useful information for the end user. The facts being consolidated can be facts from different web sources as well as from others subscribing with comparable IOT gadgets [16].

\section{d) Delivery of Information}

The last step is delivery of useful information to the end user [16], this may be a customer, a commercial or an industrial user. It may also be another device in the M2M workflow. The aim in a customer use case is to provide the information in as simple and transparent a method as possible, [16] notes.

\section{RELATED WORKS}

[17] Notes that India is one of the greatest agricultural land in the world with about 179.9 million hectares under cultivation. Still in India, meal grains are saved at warehouses using the usual manual method which leads to problems such as theft, rain, flood, variant in temperature and humidity, attacks of rodents, insects etc. the authors proposed and integrated smart sensing devices with Internet of Things (IOT) and Wireless Sensor Networks to preserve the quality and quantity of the stored products over time. According to [17] the device has capability of being controlled and monitored from remote location and delivering real time notification without human intervention. The proposed system made use of Raspberry Pi 3 Model B+, Sensors (PIR, Temperature and Fire), Ultrasonic Ranging Device, Web Camera, Buzzer, Software Requirements, Java, Win forms using c \#. Net and Android studio. From this author we note that the focus was on monitoring grain quantity and quality by making use of temperature sensors for room temperature in which the grain is stored, PIR for motion sensing as well as fire sensors, however it is not clear on how the sensor data was being stored.

The study by [18] proposed an amusing and low-cost administration platform to recognize real-time monitoring and tracing for prepackaged meals for the supply chain based on Internet of Things (IoT) technologies and eventually make sure a nonthreatening and protected meals consumption environment. Following service-oriented architecture, a flexible layered architecture of tracking and tracing platform for prepackaged meals was to be developed. Besides lowering the implementation price whilst realizing fine-grained monitoring and tracing, a built-in solution of the usage of each the QR code and radio-frequency identification (RFID) tag was proposed. Furthermore, Extensible Markup Language (XML) was adopted to facilitate the information sharing amongst functions and stakeholders. In this study we observe the adoption of RFID and QR code for tracking and tracing of prepacked food in their supply chain, however the study does not show how the implementation was achieved as it only proposed the adoption of the said technologies.

[19] Proposed and developed a GSM Based Home Security System Using PIR Sensor, the system according to [19]was very simple. In their system PIR sensor was used for sensing and then microcontroller was used for controlling. GSM module was used for SMS and calling purpose. When anybody comes in range of PIR sensor, the sensor sends a signal to the microcontroller and takes control and perform a given job. [19] Adds that Home security system using PIR sensor can be been implemented for security concerns. The system would then make a call to the user when any intruder is detected inside a room. According to the author the results presented showed that the system was cheap, implementation is easy, Low power consumption and automated operation. However the gap noticed in this system was a lack of storage provision of the SMS alerts, storing alerts is important as it is easy to make reference to past intrusions and help make better decisions on how best security measures could be improved upon. 


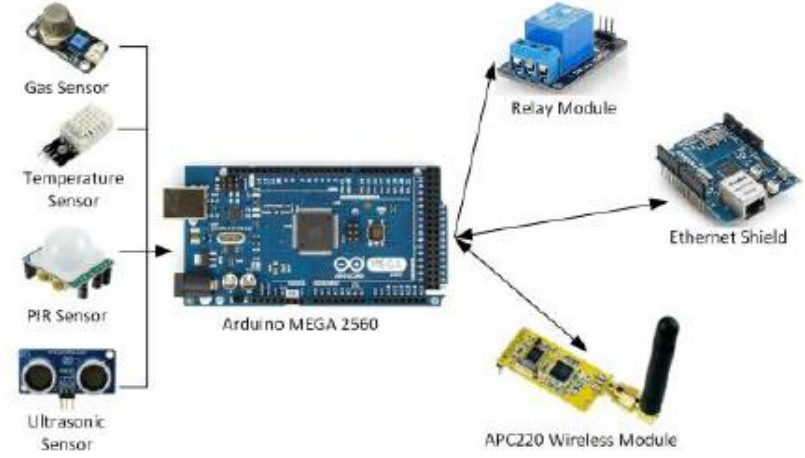

Fig. 3. Actual Hardware Implementation [20].

TABLE II. EXPERIMENTAL RESULTS OF APC220 WIRELESS COMMUNICATION MOdULE [20]

\begin{tabular}{|c|c|c|c|c|}
\hline \multirow[b]{2}{*}{ Scenario } & \multicolumn{4}{|l|}{ Trials } \\
\hline & No of trials & $\begin{array}{l}\text { Success } \\
\text { trials }\end{array}$ & $\begin{array}{l}\text { Failed } \\
\text { trials }\end{array}$ & $\begin{array}{l}\text { \%Error } \\
\text { (failed total } \\
\text { trials) }\end{array}$ \\
\hline Line of sight & 10 & 10 & 0 & 0.00 \\
\hline $\begin{array}{l}\text { Across } \\
\text { Building }\end{array}$ & 10 & 10 & 0 & 0.00 \\
\hline
\end{tabular}

[20] In Malaysia proposed a smart home system using internet of things and four types of sensors including PIR, temperature, ultrasonic, and smoke gas sensor for automatic environmental control and intrusion detection. In their proposed paper, experiments on various sensors were conducted. Next, the communication channel using wireless and Ethernet modules were also discussed. Additionally, the authors said solar charger enhanced the availability of their prototype system. Results showed the effectiveness of proposed smart home system in the prototype and real life experiments [20]. Figure 3 shows the actual hardware implementation they had proposed.

[20] Also conducted an experiment to evaluate the wireless communication module on line of sight and across the building. Table II below shows results that were presented

The overall performance of the system was verified with very low percentage error [20], several experiments were conducted to evaluate the suitability of the selected sensors, as well as the data communication modules using Ethernet W5100 and APC220 Wireless communication. All the sensors and data communication modules were connected to Arduino as the IoT platform. The focus of study by [20] was muchly on experimenting and testing the effectiveness of selected sensors, wireless communication modules and Ethernet cables.

[21] Conducted an experiment called alarm based human motion detection, an embedded system which they used to provide security. [21]Adds that this system was better as opposed to having a manual security system, [21] notes that the use of alarm based detection system for detecting human motions to provide security reduces man power and is very affordable. When a person moving around the circuit, PIR sensor detected the change in the IR levels of surroundings then the system sends a signal to the microcontroller [21]. Features of their proposed system was that it is very cheap and affordable, It is efficient and portable that means it can placed at any place easily, very easy to use and Maintenance cost is low. It was observed that study by [21] made use of motion sensing to provide an alarm in case of intrusion at home as a means of security. Further in this system there is no provision of SMS alerts, phone call and storage of the alerts in case the home owner is not at home and an intrusion occurs.

[22]Aimed at making a smart surveillance system using Raspberry Pi along with PIR sensor and Raspberry Pi-Camera. PIR sensor was used to detect the motion whenever someone comes within its range. As soon as PIR Sensor detects the motion, Pi-Camera activates and captures an image. This image is then stored in the system and finds for a human face in the captured image using Python. [22] Further notes that by using motion detection, it saves the monitoring time and cost and has it has gained a lot of interests over the past few years. The system also uses GSM/GPRS technology, so that they can use long heave communication for the monitoring section and allow for the system to be pragmatic in real time.

[23] Proposed Internet of Things and Wireless Sensor Network that lead to agricultural transformation. They also designed, tested and explored an "Internet of Thingse based device which is capable of evaluating the sensed information and then conveying it to the intended user. The device is controlled and monitored from remote location and it can be applied in farming fields, grain stores and cold stores for security purpose [23]. In this device revealed sensors and electronic devices are integrated using Python scripts. And in this system IP based CCTV security cameras entail network connectivity for monitoring from far-flung locality.

[24] The paper proposes a novel security framework in light of Open source cloud server "things speak com" and a minimal cost esp8266 Wi-Fi module. The task incorporates a PIR module which always monitors the Home or Work space .When the PIR module recognizes a trespasser it sends a flag to the microcontroller and the controller is associated with an Esp8266 Wi-Fi module and furthermore to an alert framework. The System transmits an alarm flag to think speak which gives an alarm motion on the clients' cell phone. The framework utilizes a second esp8266 module which is modified to go about as a web server and enables the client to actuate or deactivate the security framework by means of any gadget with the internet. The framework additionally utilizes a thumb print reader which controls the opening and the end of a locker entryway. In this way the framework utilizes Wi-Fi module and microcontroller to control the security framework from the client's cell phone.

[25] Acknowledges that the Internet of Things (IOT) is the driving force for a great deal of innovation and economic activities. The proposed project expands on the concept of IoT to agriculture. [25]Notes that farm equipment's are costly and their theft is a very common problem faced by farmers. The purpose of the project was to make a device which would help them to monitor their farm equipment's and prevent theft. Implementation consists of sensing parameters like motion of the object and location of the device and alerting them in case of any variation in their position or motion through mobile phone. A wireless network was setup between farm devices 
and a central server which will further communicate with Android Application which would then receive alarm of theft and location of the device using global positioning system (GPS) of theft device.

[26] Proposed a prototype to reduce the theft of farmer input such as fertilizer under Farmer Input Support Program (FISP) in Zambia. The prototype used barcodes placed on bags to identify each bag and record the data in a database housed in the cloud. Upon distributing the bags to farmers, the database updates are made to reflect the changes in inventory levels. The input inventory management system was set to control the theft of inputs that stood at $56 \%$ in the warehouses. From the baseline study conducted by [26] the results show theft occurrence at the satellite depot, holding depot and during transportation. The main contribution in this paper was the use of cloud storage, the system did not however provide for warehouse storage mechanism despite the authors findings which showed high percentage of theft.

[27] Designed a wireless remote sensor network based on android things for monitoring environment conditions in storage warehouses for the Food Reserve Agency in Zambia. The system used sensor nodes to monitor temperature, humidity, water and motion. The temperature, humidity and water were used to monitor the state of the storage environment while the motion sensor was used to detect the presence of intruders. The data from the sensor nodes was sent to an aggregator node via ZigBee and later transmitted to the server in the cloud using a GSM network. The cloud storage service used was third party which may be inappropriate for storing data for a government agency. However the prototypes did demonstrate the use of ZigBee in environmental monitoring. In their system there is also no provision of the usage of the Web application for a more visualized sensor values.

[28] Proposed an Application of Internet of Things (IoT) in Supply chain management of Agricultural products. Here they designed a website for the farmer and manager. Using the Radio Frequency identification (RFID) technology, agricultural products are tracked at every stage of supply chain, The RFID tag is attached to the product container and scanned against RFID reader and ESP8266 at every stage of SCM. Once the tag is scanned that tag id is uploaded to the database. The product information is uploaded by the farmer through the manager. The main objectives were: Automatic identification of agricultural products, Global tracking and tracing of agricultural products, providing the complete information of the whole life cycle of the product to the farmer inorder to achieve transparency in the system. There exist a number of literature based on the implementation of IoT [29], [30], [31], [32], [33], [34], [35], [36], [37].

From the proposed and implemented experiments/ projects reviewed from literature, it has been observed that there is substantial potential to be tapped from the use of internet of things in agriculture and other sectors. We also note that there exist a number of research gaps in the sense that many authors merely proposed there prototypes and explained there benefits without putting these prototypes to full use. In line with our objectives and related literature reviewed we note that most experiments or projects did not make use of cloud storage, IoT Sensors have the ability to generate large volumes of data at a high rate and that poses a huge challenge because more storage space is required to keep the data, therefore cloud storage comes in to address the challenge. [38]Points out that having a centralized store of data puts real-time data in the hands of decision makers.

The literature reviewed was also the basis of the researcher's theoretical model for intrusion detection in the grain storage warehouse and grain tracking. For intrusion detection (e-perimeter) literature suggests Apc220 a wireless radio communication module as it offers no line of sight problems, GSM for SMS alerts and for data transfer to the cloud storage GPRS, Passive infrared(PIR) for motion detection, and open source microcontroller Arduino boards as our IoT platform as the hardware is less expensive. Apc220 transceiver offers no problem with line of sight and across buildings, has low power consumption, security and control capabilities, signals travel in the transmitter and receiver even when there is an obstruction which makes it suitable for security systems. For grain tracking literature suggests radio frequency identification (RFID) as it offers automatic identification of agricultural products, Global tracking and tracing of agricultural products. Also providing the complete information of the whole life cycle of the product so as to achieve transparency in the system, GPRS for transferring data to the cloud.

\section{PRoposed Model PROTOTYPE}

The proposed model seeks to address the gaps in grain theft at FRA warehouse storage using motion sensing and grain tracking using RFID. The mapped current FRA business processes are presented in the study by [1].

The researchers proposed model is based on the current FRAs business processes but with a focus mainly on warehouse storage and grain tracking and tracing. The proposed IoT model is divided into two, intrusion detection which is achieved by putting in place an E-perimeter to monitor unauthorized entry in the restricted zone were the grain shall be stocked so that the grain is secured, the IoT technologies adopted for this module are Wireless data communication module APC220, GSM to alert management by sending an SMS once motion detection happens with the help of the motion sensors, GPRS via an HTTP GET REQUEST for data transfer to the cloud database and PIR (passive infrared) because these are mainly for intrusion detection, it is also capable of detecting any trespassing that occurs in the range of the motion sensor. The second module responsible for grain tracking, once the grain bags are tagged and ready for dis-patch, this module shall also be used for tallying so as to compare the number of dispatched bags against the received from one depot to another within the FRA circulation, this shall be achieved by the use of an IoT device called Radio Frequency Identification (RFID) to uniquely identify each bag, additionally we shall use GSM, GPRS modules that are embedded in the SIM808 communication module. Figure 4 below shows the proposed model business process for FRA. 


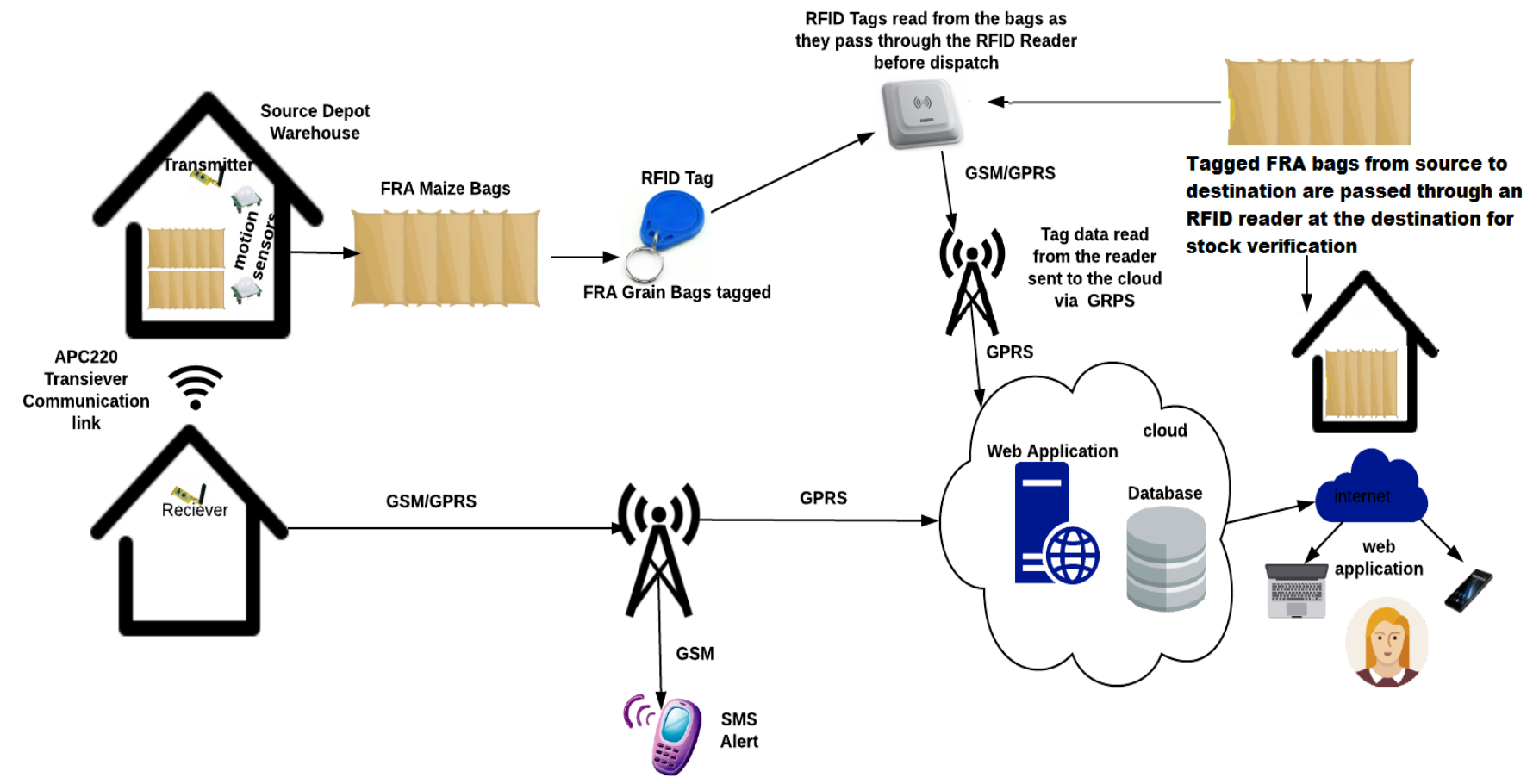

Fig. 4. Proposed IoT based Business Process Model for Warehouse Intrusion Detection and Grain Tracking.

\section{MATERIALS AND METHODS}

The main purpose of this research is to help food reserve agency solve the current theft problem by developing a grain tracking and e-perimeter system prototype that is cost effective. So the researcher made use of the components that have effective operation and usage. In this section, hardware parts, i.e. hardware components used for the project are outlined.

1) Materials: Material/ components for intrusion detection include:

- GSM/GPRS Module (SIM808)

- Arduino Uno (Micro controller)

- Passive Infrared (PIR) Sensors

- Apc220 Wireless Communication Modules

Material/ components for grain tracking include:

RFID Reader module

\section{RFID tags}

GSM/GPRS Module (SIM808)

Arduino Uno (Micro controller)

Software requirements

- PHP for the web application

- $\mathrm{C}++$ for the microcontroller programming

- CSS Bootstrap for styling

- Java script
- MySQL remote database

- Apache remote Webserver

- Arduino IDE

2) Methods: The method adopted for testing and developing our prototype model was experiment based that enabled us to break down our work into modules namely the warehouse intrusion detection (e-perimeter) and the grain tracking module.

\section{A. Warehouse Intrusion Detection (E-Perimeter)}

In this experiment a linear array of 2 Passive Infrared Sensors (PIR) are connected to a microcontroller (Arduino) at the transmitting end. The PIR constantly senses from an infrared inference given off by a human or animal. Upon breakage of the infrared flux, a signal is generated and sent to the micro controller using the digital connection bus. The embedded program parses the signal and transmits it to the receiving end as an integer " 1 " to signify intrusion or " 0 " to signify a void wirelessly using the included Omni-directional wireless radio receiver-transmitter. The receiving end is fitted with an Omni-directional receiver-transmitter, it receives the given flag; i.e. an integer signifying intrusion or a void. The embedded program then sends an SMS alert to a predefined cell phone number using the connected GMS module over the GSM network, simultaneously upon sending of an SMS alert via GSM network, GPRS using the HTTP GET request is used, the application on the remote server is invoked to parse the alert data and insert it into the cloud database for storage. A summarized working of this module is presented in a flow chart in figure 5 below. 


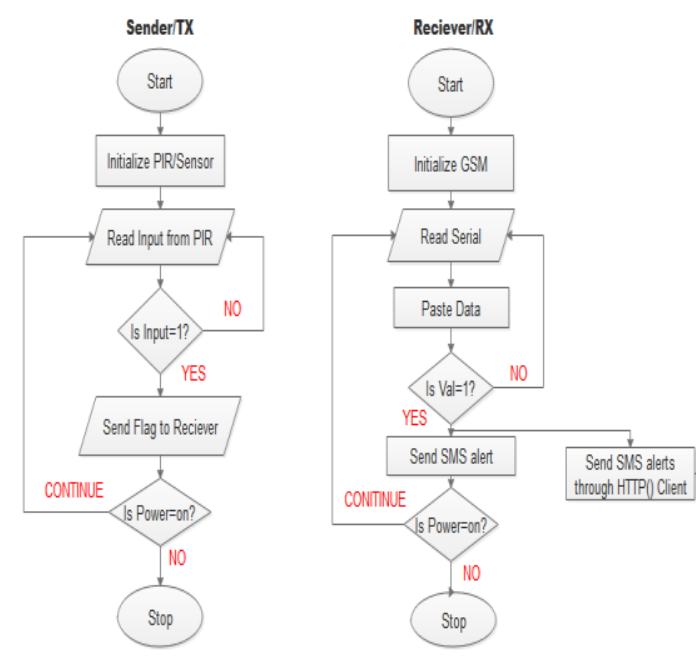

Fig. 5. Flow Chart Working of the Intrusion Detection Module.

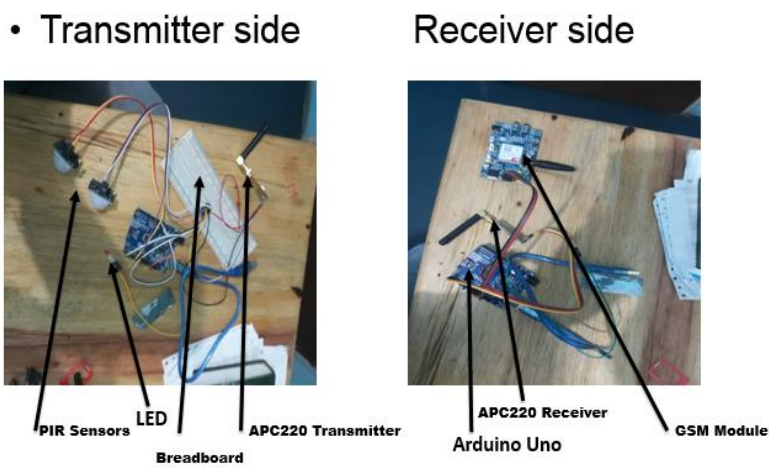

Fig. 6. Hardware Setup of the Intrusion Detection System.

\section{B. RFID Grain Tracking Module}

The communication paradigm in the RFID setup is similar to that of the intrusion detection module mentioned above.

An RFID reader module is connected to a microcontroller (Arduino), bags of produce are tagged with RFID tags then each bag is scanned upon delivery as well as dispatch point. At the scanning point is the buzzer that gives a signal in form a buzz once the tag has been read. On delivery the quantity of the produce at a given warehouse is incremented in real-time in the cloud database. The opposite happens when a bag is scanned at dispatch. The RFID scanning device is embedded with a warehouse or depot id, this warehouse id is sent along with the tag id through a parameterized URL to the remote server via GPRS. Then the server side application on the application layer of IoT parses and stores the received parameters in the remote database. Further when an RFID tag is read, its id information is stored remotely by the application, the designated store id then is used to increment quantities in the related store. The RFID setup tracks the amount of produce at a specific warehouse to reflect current quantities. This information is overlaid on an interactive satellite map alongside other warehouse information. The application makes use of the Arduino microcontroller, GSM and GPRS module as well as RFID. The hardware setup of this module is depicted in figure 7 below, and the working algorithm depicted in a flow chart in figure 8 .

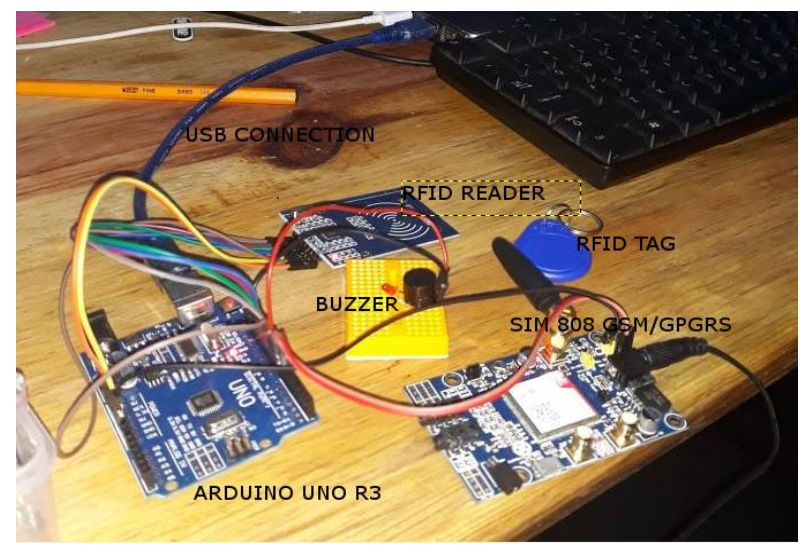

Fig. 7. Hardware Setup of the RFID Module.

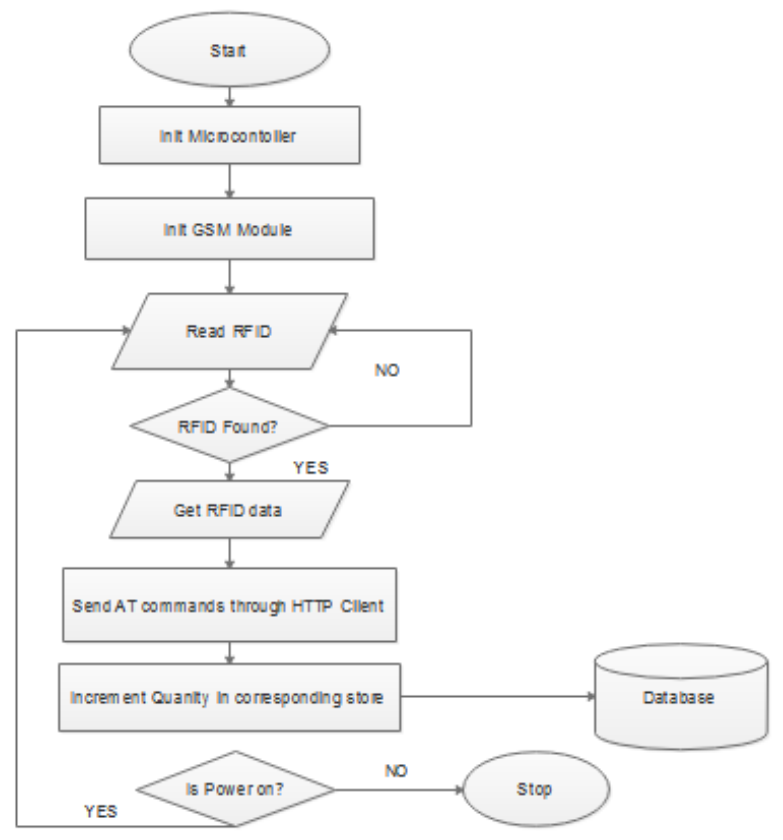

Fig. 8. Flow chart of RFID Grain Tracking.

C. Result

\section{a) E-Perimeter Results}

The e-perimeter prototype hardware in figure 6 was put to a test. Below is the figure 9 showing how the intrusion can be detected.

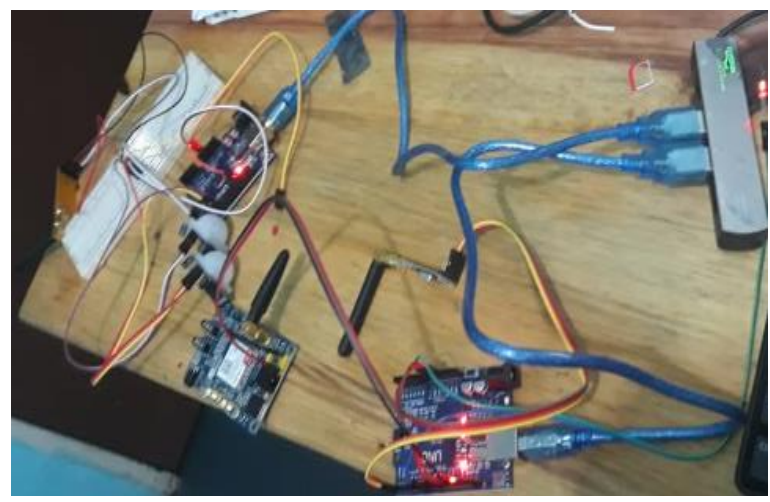

Fig. 9. Motion Intrusion Testing. 


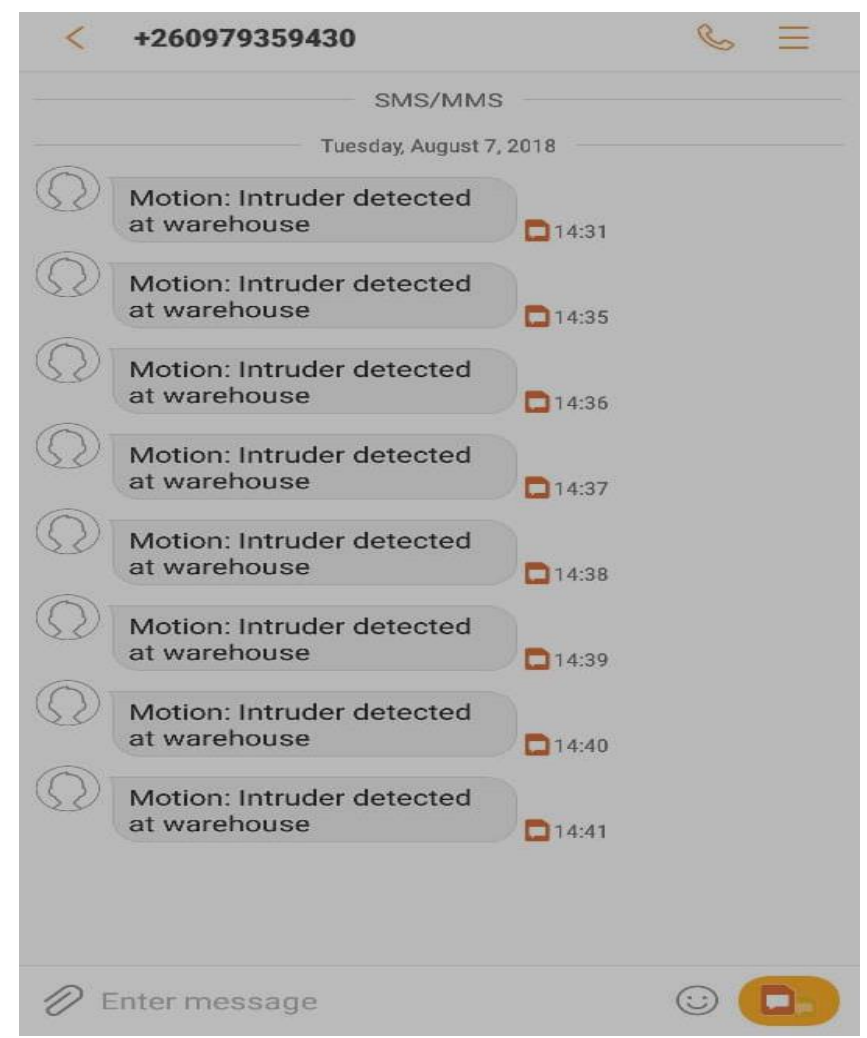

Fig. 10. SMS Alert to the Pre-defined Number.
To detect motion the intruder has to be in the range of 7 meters and any range below 7 meters because that is how far the PIR motion sensing can detect. However this setup forms a wireless sensor network, that is we have a sensor node, microcontrollers and transceivers, this implies that the communication between two apc 220 transceivers should be wireless, so both the transmitter and the receiver have to be in the same network to communicate wirelessly. In the experiment of figure 10 motion sensors are set up at the sensor node, what was observed was an LED flashing light when an intruder comes in the range of the sensor node. As the motion got detected the transmitter on the sensor node transmitted the motion value to the receiver side in this network that received the sensor value and checked to confirm the received value and through the GSM module once the received value is confirmed to be that of motion an SMS alert through the GSM is sent to the designated number to alert them on the intrusion. The figure below shows the received alert message.

For monitoring the alerts on our web application we developed a web application which is hosted in the remote cloud server. The web application was developed using PHP, HTML, Bootstrap and JavaScript. The web application interface for alerts allows the administrators to view alerts of the warehouse intrusion, the warehouse name is captured so that it easy to know which warehouse had an intrusion, the intrusion time is also captured and the alert message. Figure 11 shows the alerts application view, the view gets updated as and when new intrusions are recorded.

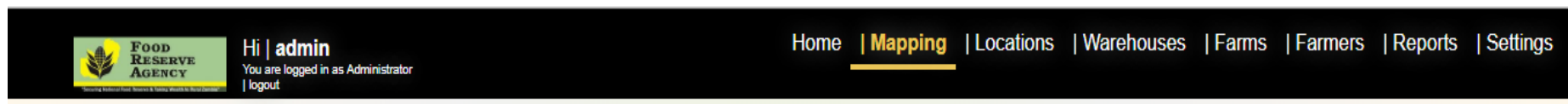

\section{Alarms}

\begin{tabular}{lll}
\hline Search (Warehouse name) & Go! \\
\cline { 2 - 3 } Warehouse Name & Intrusion Time & Message \\
\hline Zam Stores & Tuesday,August 07 - 2018 at 08:41:32am & Intruder detected at warehouse \\
\hline Zam Stores & Tuesday,August 07 - 2018 at 08:40:13am & Intruder detected at warehouse \\
\hline Zam Stores & Tuesday,August 07 - 2018 at 08:39:19am & Intruder detected at warehouse
\end{tabular}

Fig. 11. Cloud Application of the Alarms.

\section{b) Grain Tracking using RFID Results}

The RFID tags are scanned against the RFID reader as can be seen in fig 12. After a successful scan the tag data is sent to the Arduino, the Arduino through sim808 GSM/GPRS module sends the scanned data to the cloud. Once the tag data is received and stored in the database, it is later overlaid on the google map embedded on the PHP webpage as spatial data together with other warehouse information. Quantity on the info window is representing the scanned RFID tags that are representing grain bags, the rest of the information showing on the info window of the warehouse is added by the admin upon creation of the warehouse. Fig 13 below shows the warehouse spatial data before scanning of the tags and Fig 14 after scanning.

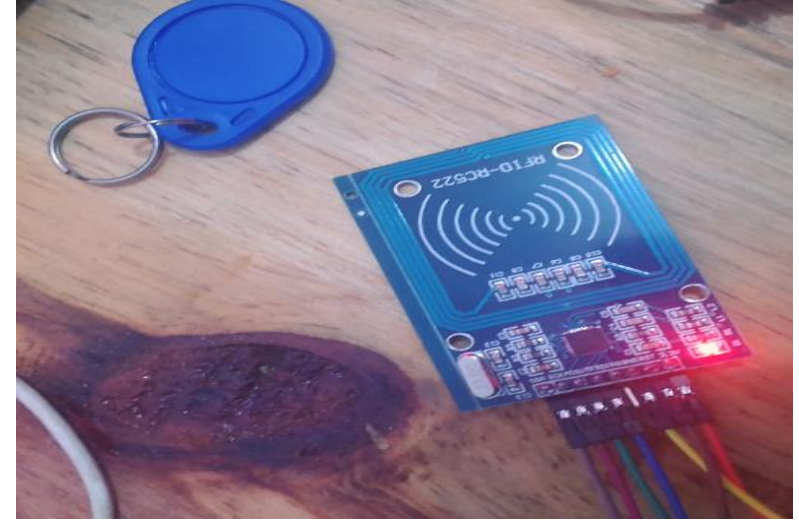

Fig. 12. Tag scanning Against the RFID Reader. 


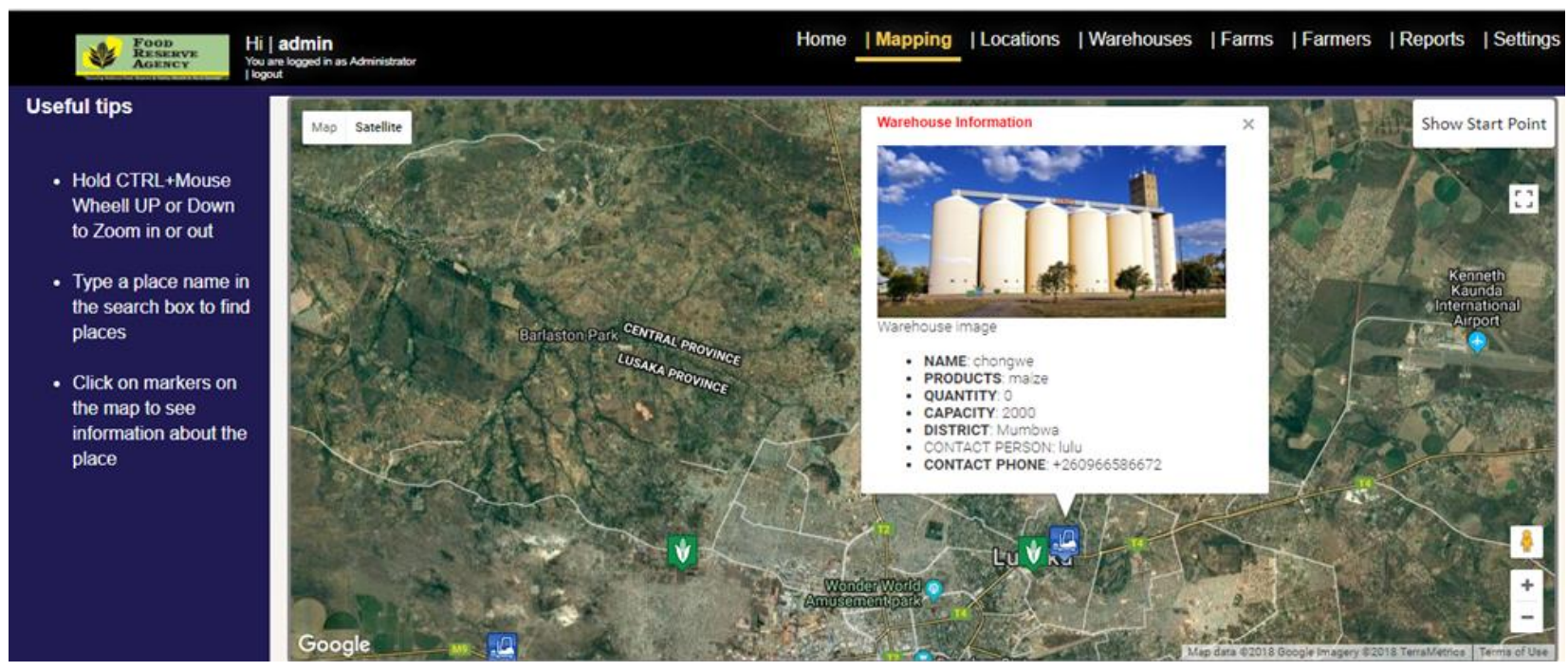

Fig. 13. Before Scanning.

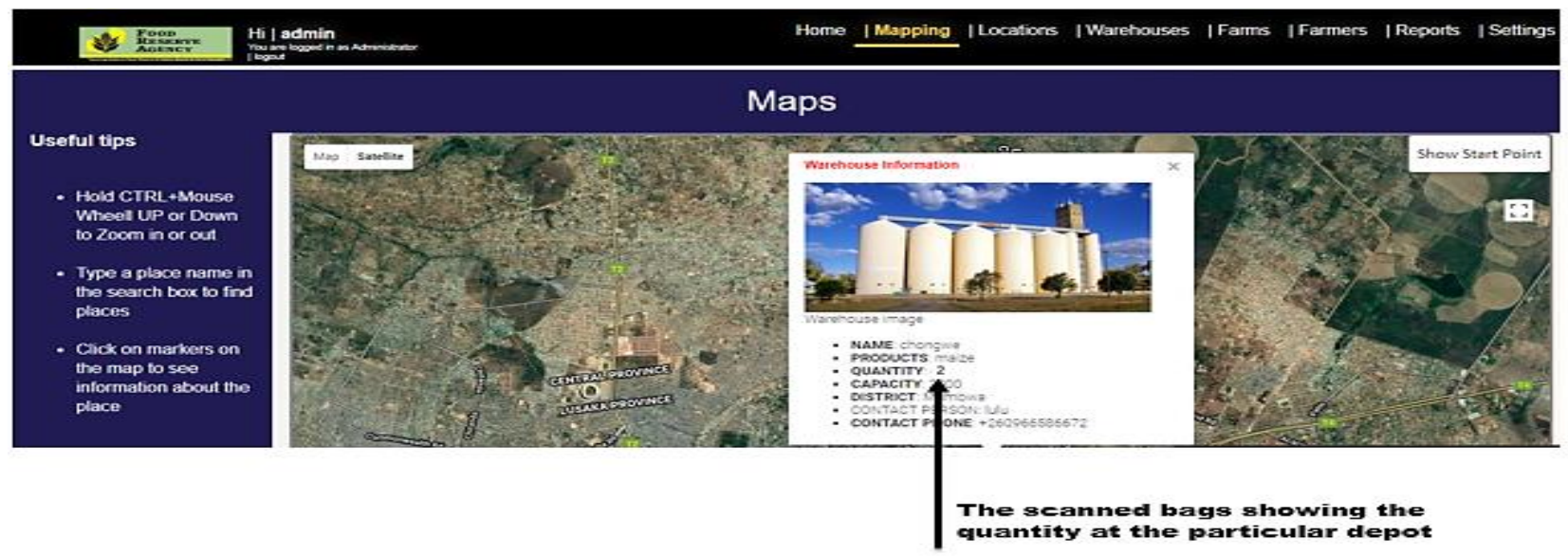

Fig. 14. Quantity Overlaid on an Interactive Satellite Map Alongside Other Ware House Information.

\section{Findings}

The experiment conducted was our proof of concept to ascertain the working of the prototype model that was proposed. From the experiment conducted it has been noted that the model proposed is not just a layout of the processes but the practicality behind it is possible as we have tested our modules and the methods we utilized proved beyond doubt that they are a better option for FRA grain management. The results achieved through the use of IoT is evidence enough that this is the route to take in order to reduce on theft at grain storage points(depots), further with the employment of RFID in FRA circulation security would be achieved as the grain moves from one depot to another verification by way of scanning and serving to the cloud as well as displaying the scanned quantities on the map will improve upon accountability as it would be easy to track the grain from source to destination in terms of its quantity. However from the intrusion detection (eperimeter) module we the author observed that due to the blocking (synchronous) nature of the GSM module in use, the number of services that can be deployed on a single module would mean sacrificing the "real-time" paradigm which is paramount to monitoring in the e-perimeter application. This means when the perimeter is breached the GSM module must then begin to transmit alert messages by means of SMS and sending an HTTP REQUEST to the cloud application, this further implies changing the operation modes whenever communication occurs which in turn creates a blind-spot in the monitoring application as the GSM module ignores any other intrusions occurring while it is processing. This however can be overcome by implementing an array of GSM Modules as a future development in order to promote asynchronous operation of the alerting service, that is a single GSM module will be dedicated to performing a single function in the processing and transmission or alerts through appropriate channels hence blocking is alleviated since no module will have to wait for any in order to transmit an alert over a specific operation mode.

\section{DISCUSSION AND CONCLUSIONS}

From the proof of concept experiment carried out on the proposed IoT prototype based warehouse intrusion detection (e-perimeter) and grain tracking model, it has been observed that once these methods are adopted by the food reserve agency, food security will greatly improve as the sole aim of these methods are to reduce the chances of theft at FRA, and 
the various ways in which these methods will bring about improvement in food security are that national resources will be preserved i.e. the money invested in buying of grain will be reduced as security mechanisms would be in place. Further the proposed methods will bring about efficiency in handling and managing grain and depots dotted around the country. These methods will also make it easy for FRA in terms of prosecuting would be offenders as and when theft is involved as there will be evidence readily available in form of the alert reports and other related data stored in the cloud database. Food reserve agency being the back born of Zambia's economy in terms of food security needs to improve on food security and management to meet the growing food needs due to population increase.

Based on the objectives of this study the authors arrived at the following conclusions that Internet of things based technologies RFID, WSN and cloud storage utilization reduces occurrences of theft and administrative errors, and aids in significantly improving efficiency and accountability. It was further drawn from the experiment and observation analysis on the model that the agency had an advantage of the modern proposed technology in this research.

\section{ACKNOWLEDGMENT}

The authors would like to thank God almighty for the grace of good health, his mercies and grace upon us. Most importantly the grace he accorded us in our research endeavors.

\section{REFERENCES}

[1] L. M. Cynthia and P. Jackson, "A Wireless Sensor Network Based Grain Inventory Management System for Zambia's Food Reserve Agency," IJIRSET, vol. 5, no. 3, pp. 3519-3526, March 2016.

[2] FAO, "Report of the World Food Summit," FAO, Rome, 1996.

[3] M. Nicole, S. T and J. Robert, ZAMBIAN SMALLHOLDER BEHAVIORAL RESPONSES TO FOOD RESERVE AGENCY ACTIVITIES, Lusaka, 2011.

[4] FAO, Global food losses and waste: Extent, Causes and Prevention, 2011.

[5] O. C. Anna, "FRA Audit report," Lusaka, 2009.

[6] C. Mulima and J. Phiri, "A Remote Sensor Network using Android Things and Cloud Computing for the Food Reserve Agency in Zambia," (IJACSA) International Journal of Advanced Computer Science and Applications, vol. 8, no. 11, pp. 411-418, 2017.

[7] W.-S. Charlie, J. T and M. W, "THE IMPACT OF REDUCING FOOD LOSS IN GLOBAL COLD CHAIN," University of Norttingham, Norttingham, 2015.

[8] Dr.N.Suma, S. R. Samson, S.Saranya, G.Shanmugapriya and R.Subhashri, "IOT Based Smart Agriculture Monitoring System," International Journal on Recent and Innovation Trends in Computing and Communication, vol. 5, no. 2, p. 177 - 181, February 2017.

[9] V. N. Malavade and P. K. Akulwar, "Role of IoT in Agriculture," in National Conference On "Changing Technology and Rural Development" CTRD, 2016.

[10] E. C. Laxmirajam and D. R. S. Kawitkar, "A Survey: IoT based Vehicle Tracking System," International Journal of Advanced Research in Computer and Communication Engineering, vol. 6, no. 5, pp. 791-795, 2017.

[11] Soumyalatha and S. G. Hegde, "Study of IoT: Understanding IoT Architecture,Applications, Issues and Challenges," in 1st International Conference on Innovations in Computing \& Networking (ICICN16), Bangalore, 2016.

[12] E Ankit, K. Jekishan and S. Chaudhary, "Internet of Things: Architecture and Research Challenges," CSI Communications, pp. 21-25, June 2016.
[13] Z. Ying-conga and Y. Jingb, "A Study on the Fire IOT Development Strategy," International journal of safety and security engineering, vol. 4, no. 2, p. 135-142, 2014.

[14] A. Khalid, "Internet of Thing Architecture and Research Agenda," International Journal of Computer Science and Mobile Computing, vol. 5, no. 3, p. 351 - 356, March 2016.

[15] D. Bandyopadhyay and J. Sen, "Internet of Things - Applications and Challenges in Technology and Standardization," Wireless Pers-commum, 2011.

[16] S. Choudhari, T. Rasal, S. Suryawanshi, M. Mane and P. S. Yedge, "Survey Paper on Internet of Things: IoT," International Journal of Engineering Science and Computing, vol. 7, no. 4, pp. 10564-10567, 2017.

[17] P. Kavya, K. Pallavi, M. Shwetha, K. Swetha and M. B. S, "Use of Smart Sensor \& IoT to Monitor the Preservation of Food Grains at Warehouse," International Journal for Research Trends and Innovation, vol. 2, no. 6, pp. 449-454, 2017.

[18] Z. Li, G. Liu, L. Liu and X. Lai, "IoT-based tracking and tracing platform for prepackaged food supply chain," Industrial Management \& Data Systems, vol. 117, no. 9, pp. 1906-1916, 2017.

[19] K. A. Rajani U S, "GSM Based Home Security System Using PIR Sensor," IJECT, vol. 8, no. 2, April-June 2017.

[20] S., , Teddy, R. Intan, Y. Husna, K. Mira and M. Hasmah, "Performance Evaluation of Smart Home System using Internet of Things," International Journal of Electrical and Computer Engineering (IJECE), vol. 8, no. 1, pp. 400-411, February 2018.

[21] K. Ajay, R. Prince, K. Justice and A. Mr, "MOTION DETECTION USING PIR SENSOR," International Journal of Scientific Development and Research (IJSDR, vol. 1, no. 5, pp. 103-106, 2016.

[22] A.Nivedha, V.Soundariya, J. C and K. Shaik, "Internet of Things - Smart Surveillance System using PIR Sensor with Raspberry Pi," International Journal on Future Revolution in Computer Science \& Communication Engineering, vol. 4, no. 4, p. 22 - 24, April 2018.

[23] B. N. Tanmay and k. p. Pushpendra, "Development of IoT based Smart Security and Monitoring Devices for Agriculture," in 6th International Conference- Cloud System and Big Data Engineering (Confluence), 2016.

[24] Safa.H, P. ,. Sakthi, G. P. Vikkashini, S. Vishnupriya and Boobalan.T, "IOT based Theft Premption and Security System," International Journal of Innovative Research in Science,Engineering and Technology, vol. 5, no. 3, pp. 4312-4317, March 2016.

[25] P. S. Kushal, s. j. Mahendra, k. Santosh and D. A. Jain, "IoT based Theft Detection and Alarming System for Farm Equipment," Sinhgad Institute of Management \& Computer Application(SIMCA), pp. 1-5, 2016.

[26] J. Chomba and J. Phiri, "Using the Cloud Architecture to Automate the Farmer Input Support Programme (Fisp) Inventory System," International Journal of Sciences: Basic and Applied Research (IJSBAR), vol. 28, no. 3, pp. 231-244, 2016.

[27] M. Chibuye and J. Phiri, "A Remote Sensor Network using Android Things and Cloud Computing for the Food Reserve Agency in Zambia," (IJACSA) International Journal of Advanced Computer Science and Applications, vol. 8, no. 11, pp. 411-418, 2017.

[28] S. Shambulingappa H and D. Pavankumar, "Application of IOT in Supply Chain Management of Agricultural products," International Journal of Engineering Development and Research, vol. 5, no. 3, pp. 863-867, 2017.

[29] P. A. Shinde and Prof.Mr.Y.B.Mane, "Advanced Vehicle Monitoring and Tracking System based on Rasberry Pi," in IEEE Sponsored 9th International Conference on Intelligent Systems and Control (ISCO), 2015.

[30] M. P. R. Joshi, M. V. V. Patil, M. P. S. Koli and M. B. S. Tade, "DEVICE TRACKING USING EMBEDDED GPS AND ZIGBEE TECHNOLOGY," International Journal For Technological Research In Engineering, vol. 4, no. 8, pp. 1175-1180, 2017.

[31] B. Kodavati, V.K.Raju, S. Rao, A.V.Prabu and T.Appa Rao, "GSM AND GPS BASED VEHICLE LOCATION AND TRACKING," International Journal of Engineering Research and Applications, vol. 1, no. 3, pp. 616625 . 
[32] E. T and K. P, "The Smart Transportation using IoT and Intelligent Transport System in GPS Localization," International Journal of Innovative Research in Computer and Communication Engineering, vol. 4, no. 6, pp. 11197-11202, 2016.

[33] K. Priya, P. Manju, V. Mythra and S. Umamaheswari, "IoT Based Vehicle Tracking and Accident Detection System," International Journal of Innovative Research in Computer and Communication Engineering, vol. 5, no. 3, pp. 4424-4430, 2017.

[34] P. G. H, S. J. A, S. S. S., P. V. R. Kaushik and P. P. S.B., "IOT based Vehicle Tracking \& Vehicular Emergency System- A Case Study and Review," International Journal of Advanced Research in Electrical,Electronics and Instrumentation Engineering, vol. 6, no. 10, pp. 8001-8012, 2017.
[35] T. S. Gunawan, I. R. H. Yaldi, M. Kartiwi and H. Mansor, "Performance Evaluation of Smart Home System using Internet of Things," International Journal of Electrical and Computer Engineering (IJECE), vol. 8, no. 1, pp. 400-411, 2018.

[36] Dhanalakshmi1 and a. s. leni, "instance vehicle monitoring and tracking with internet of things using arduino," international journal on smart sensing and intelligent systems special issue, pp. 123-135, 2017.

[37] "IoT Based Smart Security and Home Automation System," in International Conference on Computing, Communication and Automation (ICCCA2016, 2016.

[38] S. Alinani, P. Jackson, N. Mayumbo and K. M. M, "E-governance systems: A case study of the development of a small-scale Farmer database," Zambia Information Technology (ICT)Journal, vol. 2, no. 1, pp. $7-15,2018$ 